\title{
Antibiotic prophylaxis in pulmonary surgery
}

\author{
A prospective randomized double-blind trial of flash cefuroxime versus \\ forty-eight-hour cefuroxime
}

The aim of this study was to determine whether a 48-hour antibiotic prophylaxis regimen with a second-generation cephalosporin was more efficient than a flash antibiotic prophylaxis regimen in pulmonary operations. All the included patients underwent lung resection. Patients with preoperative infection were excluded. All the patients were given cefuroxime (1.5 gm intravenously) at the time of the anesthesic induction and again 2 hours later. The randomization was done postoperatively: group 1 was given placebo intravenously $(n=102)$ and group 2 was given cefuroxime intravenously $(n=101)$, each every 6 hours for 48 hours. The overall rate of infections was $46 \%$ in the 48 -hour cefuroxime group versus $65 \%$ in the flash group $(p=0.005)$. The difference remained significant even after an adjustment with prognosis variables $(p=0.01)$. Six empyemas $(6 \%)$ in the flash group were noted versus one $(1 \%)$ in the 48-hour group $(p=0.03)$. From day 3 to day 8 after the operation, chest $x$-rays films were more often assessed as being normal in the flash group than in the 48-hour group $(p=0.005)$. On day 3 after operation, white blood cell counts were $13,020 \pm 1,220$ elements $/ \mathrm{mm}^{3}$ in the flash group versus $11,620 \pm 1,220$ elements $/ \mathrm{mm}^{3}$ in the 48-hour group $(p=0.03)$. A 48-hour antibiotic prophylaxis regimen decreases the rate of deep infections and particularly the rate of empyemas. (J ThORAC CARDIOVASC SURG 1994;107:896-900)

A. Bernard, MD, ${ }^{\mathrm{a}}$ M. Pillet, MD, ${ }^{\mathrm{b}} \mathrm{P}$. Goudet, $\mathrm{MD},{ }^{\mathrm{a}}$ and H. Viard, MD, Dijon, France

B ronchopneumonia, wound infections, and empyemas account for a $12 \%$ to $40 \%$ postoperative infection rate in lung operations. ${ }^{1-3}$ The large discrepancy in the percentages is probably a result of different definitions. Several main factors lead to infection: smoking, chronic obliterans bronchitis, alcoholism, and denutrition. ${ }^{3}$ The weakening of the immune response related to cancer and aggravated by anesthesia in addition to operation increases the infection risk. ${ }^{4-6}$ Without any proof of infection, operation is classified as "clean contaminated" because of the bronchial opening during the procedure. High tissue concentrations of antibiotics are required against the bacterial inoculum. Thus far, controlled trials on antibioprophylaxis have demonstrated only an $18 \%$ to $5 \%$ reduction in wound infections. ${ }^{7,8}$ No effect on deep infections such as bronchopneumonias or empyemas,

From the Service de Chirurgie Thoracique ${ }^{\mathrm{a}}$ and the Département d'Anesthésie-Réanimation, b Hôpital du Bocage, Dijon, France.

Received for publication Feb. 1, 1993.

Accepted for publication Aug. 2, 1993.

Address for reprints: A. Bernard, MD, Clinique Chirurgicale, Hôpital du Bocage, 21034 Dijon-Cedex, France.

Copyright $\odot 1994$ by Mosby-Year Book, Inc.

$0022-5223 / 94 \$ 3.00+0 \quad 12 / 1 / 50470$ however, has been shown. A second-generation cephalosporin is usually chosen for antibiotic prophylaxis in pulmonary operations. The aim of this study was to determine whether a longer antibiotic prophylaxis regimen for 48 hours after operation decreases the rate of deep infections in pleura, bronchii, and parenchyma.

\section{Materials and methods}

Patients were operated on in the thoracic-surgery unit at the Dijon University Hospital. All the patients involved in this double-blind randomized trial were allocated either to the flash cefuroxime* group or to the 48-hour cefuroxime group. All the patients underwent a thoracotomy with lung resection. Required indications were lung cancer, lung metastasis, or chronic pulmonary emphysema with blebs. Excluding criteria were temperature higher than $38^{\circ} \mathrm{C}$, purulent expectoration, curative antibiotic therapy that had been stopped less than 8 days, infected tumor, purulent pleurisy, lung abscess, bronchiectasis, exploratory thoracotomy, mediastinal tumor, chronic renal insufficiency, or $\beta$-lactamase allergy.

The randomization was done from the recovery room by the pharmacist who prepared the sachets containing either cefuroxime or placebo. The physician was not aware of the method used for the randomization. The code of randomization was kept secret for all patients until the end of the trial.

*Zinnat, Glaxo Pharmaceuticals, Research Triangle Park, N.C. 
All patients received a local cutaneous disinfection with povidone iodine at 12 and 1 hours before the operation. The patients were given $1.5 \mathrm{gm}$ cefuroxime intravenously at the moment of induction of anesthesia. A second cefuroxime dose was systematically delivered 2 hours later to obtain high seric concentrations until the end of the procedure. The patients were then given either placebo or $1.5 \mathrm{gm}$ of cefuroxime every 6 hours after the operation for 48 hours. The first postoperative infusion was given exactly 6 hours after the second infusion. Aerosols were given to each patient on a regular basis and a respiratory program of physiotherapy followed. All the patients were given the same postoperative analgesia. Morphinic antalgic drugs were infused intravenously every 4 hours.

Main criteria of assessment were related to the different kinds of chest deep infections and were noted from the end of the procedure to the day of discharge from the hospital. They were classified into three groups of increasing severity: (1) pneumonia defined on the basis of the $\mathrm{x}$-ray film with specific parenchymal features associated with temperatures between $37.5^{\circ}$ and $38^{\circ} \mathrm{C}$; (2) severe bronchopneumonia defined as an association of purulent expectorations and atelectasia on the plain chest $\mathrm{x}$-ray film associated with a temperature higher than $38^{\circ} \mathrm{C}$; and (3) empyemas and septicemias, recorded when associated with a temperature higher than $38^{\circ} \mathrm{C}$. As soon as a patient was in a septic condition, bacteriologic samples were obtained from expectorations, pleura, drains, and blood. Postoperative deaths and their precise cause were noted.

Minor criteria of assessment were also used: wound infection, duration of chest drainage, and time of hospitalization. Abnormal pulmonary features on plain chest $x$-ray films, expectorations, and temperature were daily recorded from day 3 to day 8 . The various features on plain $x$-ray films were classified according to severity into three classes: class 1 with normal appearance on $x$-ray film, class 2 with moderate infiltrate, and class 3 with important infiltrate or atelectasia. Expectorations were qualitatively determined as normal or purulent. Only maximal daily body temperature was recorded. White blood cell counts (WBC) were obtained on days 3 and 8 .

All randomized patients were observed and analyzed in their original group of randomization, even if they were not properly given the treatment. $\alpha$-Type 1 error and $\beta$-type 2 error were fixed at a $5 \%$ level. The infection estimated risk was $30 \%$. Our aim was to reduce the risk to $10 \%$ with $\Delta$ of $20 \%$. With a onesided alternative, we needed to include 200 patients. The quality of randomization was checked by the Mann-Whitney rank test on the patient order numbers. $\chi^{2}$ Tests were used for categorical data and Student's $t$ tests for continuous variables after checking normality and equality of variances. A logistic regression was used for adjusting the prognosis variables of the treatment. The dependent variable was deep infection, considered as a two-class variable (yes-no). We used the likelihood ratio test, which acts according to a $\chi^{2}$ law. A method of weighted least squares was used for repeated measures of categorical variables (chest x-ray films, expectorations).

This method enabled us to estimate the effect of the treatment, the effect of time, and the treatment-time interaction. We worked on marginal probabilities. The different effects were tested by a Wald test, which acts according a $\chi^{2}$ law. An analysis of variance was used to deal with repeated measures of continuous variables (temperature, WBC). ${ }^{10}$ Three factors constituted the model: a treatment factor in which the subject factor was nested, a time factor, and the interaction between treatment and time. A nonsignificant interaction may enable a global analysis. A significant interaction may require a comparison of
Table I. Main clinical features in the two groups of treatment

\begin{tabular}{lll}
\hline & $\begin{array}{c}\text { 48-Hour } \\
\text { cefuroxime } \\
(\mathrm{n}=101)\end{array}$ & $\begin{array}{l}\text { Flash } \\
\text { cefuroxime } \\
(\mathrm{n}=102)\end{array}$ \\
\hline Gender (male/female) & $91 / 10$ & $85 / 17$ \\
Age (yr)* & $56(19-78) \dagger$ & $61(17-81)$ \\
Tobacco (pack-yr) & $33(0-120)$ & $33(0-120)$ \\
Alcohol (L/day) & $0.4(0-3)$ & $0.5(0-5)$ \\
FEV (L) & $2.5(1.1-4.2)$ & $2.4(0.8-4.6)$ \\
Vital capacity (L) & $3.6(1.7-5.7)$ & $3.4(1.2-5.7)$ \\
Transfusions (units) & $0.32(0-8)$ & $0.5(0-12)$ \\
Chronic bronchitis (No.) & 30 & 36 \\
Diabetes (No.) & 5 & 4 \\
Cardiac insufficiency (No.) & 5 & 6 \\
Chemotherapy (No.) & 16 & 8 \\
Radiotherapy (No.) & 5 & 3 \\
Bad dental status (No.) & 22 & 15 \\
Diagnosis (No.) & & \\
$\quad$ Lung cancer & 81 & 79 \\
Metastasis & 6 & 11 \\
Benign tumor & 11 & 9 \\
Blebs & 3 & 3 \\
Procedures (No.) & & \\
Lobectomy & 54 & 54 \\
Pneumonectomy & 36 & 12 \\
$\quad$ Wedge resection & 11 & \\
\hline
\end{tabular}

FEV, Forced expiratory volume.

${ }^{*} T=-3.19 ; p=0.02$.

†Mean (range).

treatment at each measurement time. Results are expressed with the confidence intervals at $95 \%$. Data were processed through the BMDP (3D, 4F, 3S, 2V, LR; BMDP Statistical Software, Inc., Los Angeles, Calif. $)^{11}$ and SAS (CATMOD; SAS Institute Inc., Cary, N.C. $)^{12}$ software systems.

\section{Results}

From January 1, 1991, to June 30, 1992, 203 patients out of 369 undergoing thoracic surgery were included in the study. Of these, 101 belonged to the 48-hour cefuroxime group and 102 to the flash cefuroxime group. The features of the included patients are displayed in Table $I$. Most of the variables were balanced inside the two randomized groups except for age, which was older in the flash cefuroxime group $(p=0.02)$. More patients were given preoperative chemotherapy in the 48-hour cefuroxime group but the difference was not significant ( $p=0.07$ ). Fifteen patients $(15 \%)$ stopped smoking for more than 1 month in the flash cefuroxime group versus $18(18 \%)$ in the 48-hour cefuroxime group (NS).* The patients were correctly randomized inasmuch as the Mann-Whitney test did not show any significant difference between the two groups of treatment $(p=0.53)$.

The overall rate of infections was $46 \%$ in 48 -hour group versus $65 \%$ in the flash group ( $p=0.005$; Table II). The

*NS $=$ Not significant 
Table II. Infections with regard to treatment

\begin{tabular}{|c|c|c|c|c|c|}
\hline & \multicolumn{2}{|c|}{ 48-Hour cefuroxime $(\mathrm{n}=101)$} & \multicolumn{2}{|c|}{ Flash cefuroxime $(\mathrm{n}=102)$} & \multirow[b]{2}{*}{$\mathrm{p}$ Value } \\
\hline & $\mathrm{n}$ & $\%$ & $\mathrm{n}$ & $\%$ & \\
\hline Wound infection & 1 & 1 & 1 & 1 & 0.9 \\
\hline Pneumonia & 17 & 17 & 31 & 30 & 0.01 \\
\hline Severe bronchopneumonia & 25 & 25 & 25 & 25 & 0.9 \\
\hline Fever $\left(>38^{\circ} \mathrm{C}\right)$ & 5 & 5 & 10 & 10 & 0.09 \\
\hline Total deep infection & 47 & 46 & 66 & 65 & 0.005 \\
\hline Empyemas & 1 & 1 & 6 & 6 & 0.03 \\
\hline Fistulas & 2 & 2 & 7 & 7 & 0.045 \\
\hline
\end{tabular}

Table III. Various germs cultured from pleura, bronchii, drains, or blood

\begin{tabular}{lcc}
\hline & $\begin{array}{c}\text { 48-Hour } \\
\text { cefuroxime } \\
\text { (n) }\end{array}$ & $\begin{array}{c}\text { Flash } \\
\text { cefuroxime } \\
\text { (n) }\end{array}$ \\
\hline Staphylococcus aureus & 1 & 3 \\
Staphylococcus epidermidis & 1 & 1 \\
Streptococcus pneumoniae & 2 & 1 \\
$\alpha$-Hemolytic streptococcus & 1 & 3 \\
$\beta$-Hemolytic streptococcus & 2 & 1 \\
Nonhemolytic streptococcus & 0 & 1 \\
Hemophilus influenzae & 4 & 5 \\
Escherichia coli & 1 & 3 \\
Klebsiella & 2 & 1 \\
Pseudomonas aeruginosa & 1 & 1 \\
Citrobacter & 1 & 0 \\
Corynebacterium & 1 & 0 \\
Serratia & 0 & 1 \\
\hline
\end{tabular}

difference between the two rates was $19 \% \pm 11 \%$. The difference of infection rates remained significant $(p=0.01)$ after adjustment with prognosis variables such as age, gender, tobacco use, alcohol use, forced expiratory volume, vital capacity, chronic bronchitis, diabetes, cardiac insufficiency, dental status, preoperative chemotherapy, preoperative radiotherapy, diagnosis, type of operation, and blood transfusion. The benefit of 48 -hour antibioprophylaxis was particularly evident in pneumonia $(p=0.01$; Table II). Six empyemas $(6 \%)$ in the flash group versus one $(1 \%)$ in the 48 -hour group were noted $(p=0.03$, Table II). The various germs that were cultured were equivalent in the two groups (Table III).

Four postoperative deaths (2\%) were noted: three in the 48-hour group and one in the flash group including one caused by pulmonary embolism, one by cerebral hemorrhage, one by mesenteric infarction, and one by respiratory failure with acute bronchopneumonia.

One wound infection in both groups occurred (NS; Table II). The duration of chest drainage was $5.5 \pm 0.8$ days in the 48-hour group versus $5.7 \pm 1$ days in the flash group (NS). Hospital stay was $13 \pm 1$ days in the 48-hour group versus $15 \pm 1.6$ days in the flash group (NS).

Plain x-ray films of the chest were considered more often as normal in the 48-hour group than in the flash group $(p=0.005$; Table IV). Moderate infiltrates disappeared more rapidly in the 48-hour group than in the flash group (Table IV).

Purulent expectoration was more abundant in the flash group but without significant difference (NS). The rate of patients who were expectorating decreased from postoperative day 3 to day 8 in both groups (from 15\% to 7\% in the flash group and from $11 \%$ to $6 \%$ in the 48 -hour group).

The mean temperature was $37.2^{\circ} \pm 0.1^{\circ} \mathrm{C}$ in the 48-hour group versus $37.3^{\circ} \pm 0.1^{\circ} \mathrm{C}$ in the flash group $(p=0.045)$. The difference was more evident during the first 3 days (Fig. 1).

Analysis of variance on WBC count showed a significant interaction between treatment and time $(p=0.03)$. We interpreted both groups at each recording date. WBC count was $13,026 \pm 1,220$ elements $/ \mathrm{mm}^{3}$ in the flash group versus $11,630 \pm 1,220$ elements $/ \mathrm{mm}^{3}$ in the 48 -hour group on day $3(p=0.03)$. On day $8, \mathrm{WBC}$ count was $10,502 \pm 1,220$ elements $/ \mathrm{mm}^{3}$ in the flash group versus $10,446 \pm 1,220$ elements $/ \mathrm{mm}^{3}$ in the 48 -hour group (NS).

Five patients were not given the full treatment because of missing prescriptions: two (2\%) in the 48-hour group and five (5\%) in the flash group (NS). The cause was independent of the judgment criteria. No side effects of the treatment were noted.

\section{Discussion}

The results of this study suggest that a 48-hour antibiotic prophylaxis regimen decreases the rate of deep infectious complications with the same pattern of germs in both groups. Our results are different from those already issued on the same subject, ${ }^{1,8,13-15}$ which mainly demonstrated a reduction of wound infections. The study of Ilves and associates ${ }^{7}$ in 1981 showed a decrease in the rate of pulmonary infections with the use of a first-generation 


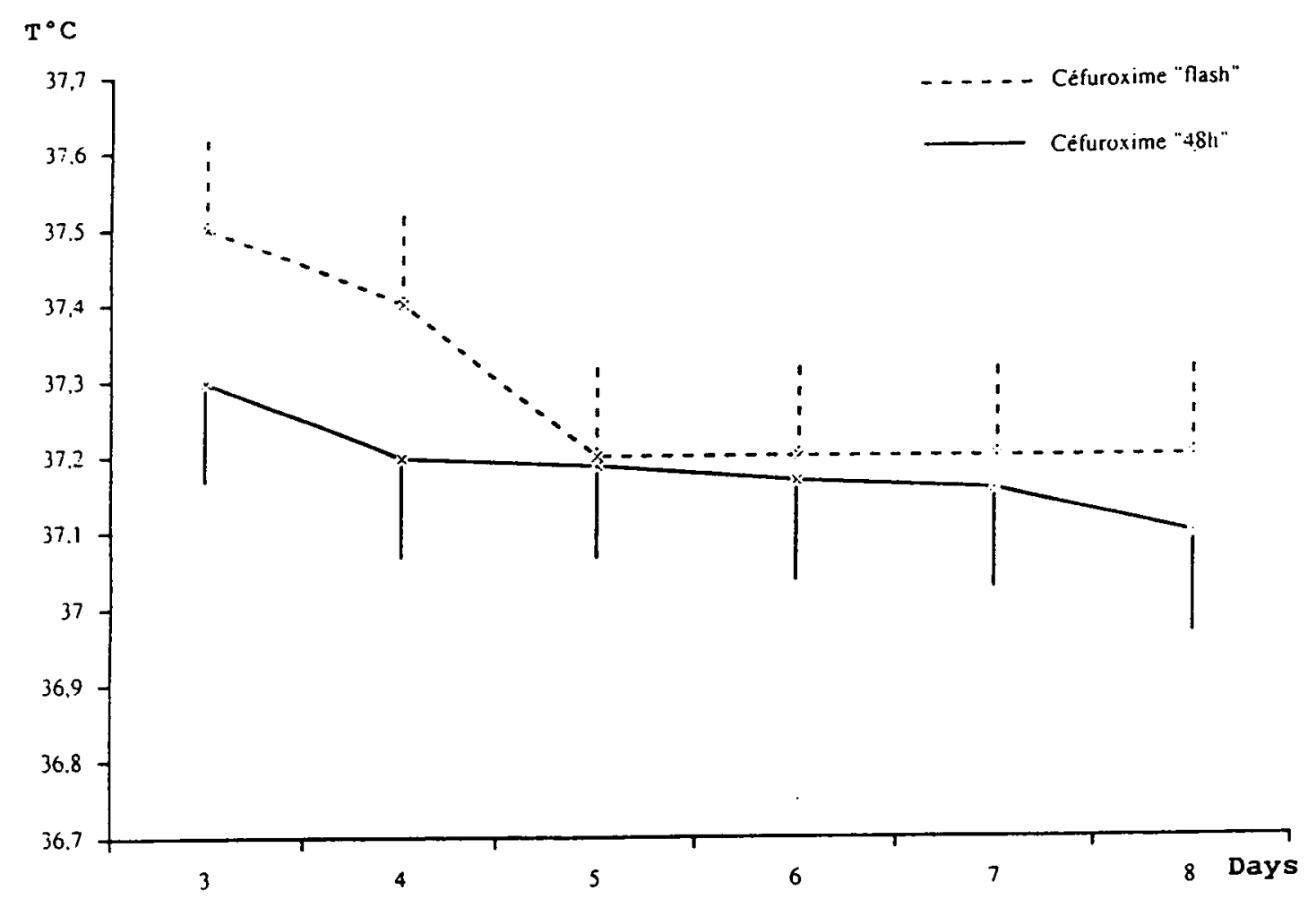

Fig. 1. Evolution of body temperature $(T)$ from postoperative day 3 to day 8 (means \pm confidence interval at $95 \%$; $p=0.045)$.

Table IV. Evolution of pulmonary images on $x$-ray films of the chest from postoperative day 3 to day 8

\begin{tabular}{|c|c|c|c|c|c|c|}
\hline & \multicolumn{6}{|c|}{ Postoperative day } \\
\hline & 3 & 4 & 5 & 6 & 7 & 8 \\
\hline \multicolumn{7}{|l|}{ Normal } \\
\hline 48-Hour cefuroxime & 62 & 62 & 70 & 76 & 78 & 79 \\
\hline Flash cefuroxime & 55 & 55 & 58 & 63 & 65 & 74 \\
\hline \multicolumn{7}{|l|}{ Moderate infiltrate } \\
\hline 48-Hour cefuroxime & 25 & 22 & 15 & 9 & 9 & 9 \\
\hline Flash cefuroxime & 35 & 34 & 32 & 28 & 29 & 19 \\
\hline \multicolumn{7}{|l|}{ Atelectasis } \\
\hline 48-Hour cefuroxime & 14 & 16 & 15 & 13 & 11 & 10 \\
\hline Flash cefuroxime & 12 & 12 & 11 & 10 & 7 & 8 \\
\hline
\end{tabular}

Numbers of patients with each class of findings are given: normal, moderate infiltrate, or atelectasia. Treatment effect: $\chi^{2}$ (Wald) $=10.5 ; p=0.005$. Time effect: $\chi^{2}($ Wald $)=51 ; p<0.0001$. Treatment/time interaction: $\chi^{2}$ (Wald $)=8.5 ; p=0.6$.

cephalosporin versus a placebo. This study cannot be compared with ours because patients receiving operations on the esophagus and hiatal hernias were included. More recently, Peyrin and associates ${ }^{16}$ reduced the rate of empyemas by using a third-generation cephalosporin versus a placebo. Yet all various trials are difficult to compare because of a large variation of antibiotics, inclusion criteria, and even definitions of bronchopulmonary infections.

Our rate of deep infections is more important than those of previous studies, which range from $12 \%$ to
$40 \% .^{1,7,8,13,15-17}$ The definition of empyema does not raise any question and its rate is comparable with that of other studies. ${ }^{15,16}$ On the other hand, the rate of bronchopneumonia is particularly high in our study and is difficult to interpret because the definition is controversial. $^{7,8,13,15,17}$ To specify this point, an independent physician daily recorded the temperature, the expectorations, and the data from $x$-ray films of the chest. We think that this infection rate might have been underevaluated in other studies and that the authors gave different definitions. $7,8,13,15,17$ 
The idea that antibiotic prophylaxis does not reduce the rate of deep infections must apparently be questioned. . $^{1,13-15}$ Too few patients are sometimes included and we can raise the question of the strength of those trials. ${ }^{13,15}$ The type of antibiotics may not have been correctly directed against the germs encountered in pulmonary operations. Some used penicillin $\mathrm{G}^{8}$ and others a first-generation cephalosporin. ${ }^{1,13,17}$

We think that flash antibiotic prophylaxis in lung operations is not a definitive procedure and that we had to challenge it. In the light of this, we included more patients, we used antibiotics correctly adapted against the lung flora, and compared the same drug with different durations of treatment.

Like Peyrin and associates, ${ }^{16}$ who used a third-generation cephalosporin with a long half-life, we proved that a 48-hour antibiotic prophylaxis regimen reduced the effects of perioperative bacterial inoculum and decreased the rate of empyemas. Moreover, the rate of pneumonia was reduced. This fact may be explained by a better prophylaxis covering a period of time when the immunologic anergy is important. On the contrary, we did not notice any change in the rate of bronchopulmonary superinfection associated with atelectasis. These infections depend on other mechanisms such as postthoracotomy pain and obstructive syndrome with stasis responsible for the superinfection.

The only study whose methods were comparable with ours drew the opposite conclusion. ${ }^{17}$ There are two ways for explaining this lack of efficiency in treating patients with a 48-hour antibioprophylaxis. First-generation cephalosporins used in the study by Olak and associates ${ }^{17}$ were not efficient against gram-negative germs or against Staphyloccocus aureus. Doses of antibiotics used were inferior to ours and did not enable sufficient concentrations to develop in the tissues. Injecting cephalosporins every 8 hours did not fit the half-life of the antibiotic and prevented them from reaching a sufficient seric concentration.

We compared the two groups of patients according to the infection rate. We calculated the required number of patients needed to prove a fall of $20 \%$ in the infection rate. The fall was $19 \%$. On the other hand, we pointed out a difference of ages between the two groups with older patients in the flash group versus the 48-hour group. To eliminate this bias, we adjusted the study by age by a logistic regression.

Some authors recorded side effects of cephalosporin antibiotics (fever, deep venous thrombosis, allergy). ${ }^{13} \mathrm{We}$ did not notice any side effects related to the treatment in the side-effect survey. Allergy to cephalosporin was an excluding criterion. No bacterial selection was noted. The panel of cultured germs was comparable with that of other studies. ${ }^{8,15}$
We conclude that a 48-hour antibioprophylaxis regimen is efficient in preventing empyemas and pneumonias. Nevertheless, our rate of severe bronchopulmonary infections remains high. Second-generation cephalosporins fit the germs encountered during lung resection operations.

\section{REFER EN CES}

1. Cameron JL, Imbembo A, Kieffer RF, et al. Prospective clinical trial of antibiotics for pulmonary resection. Surg Gynecol Obstet 1981;152:156-8.

2. Lançon JP, Caillard B, Coulon C. Les complications postopératoires de la chirurgie pulmonaire. Lyon Chir 1986; 82:14-7.

3. Laxenaire MC, Borgo J, Hartemann P. Epidémiologie des infections dans un service de chirurgie thoracique. Ann Anesth Franc 1979;20:625-31.

4. Bruce DL, Wingard DN. Anesthesia and the immune response. Anesthesiology 1971;34:271-3.

5. Girard JP, Cuevas M. Effects de l'anesthesie et de la chirurgie sur certains paramètres de l'immunité humorale. Ann Anesth Franc 1977;18:701-4.

6. Park SK, Brody JI, Wallace H. Immunosuppressive effect of surgery. Lancet 1971;1:53-5.

7. Ilves R, Cooper JD, Todd TR, Pearson FG. Prospective randomized double blind study using prophylactic cephalothin for major, elective general thoracic operations. J THORAC CARDIOVASC SURG 1981;81:813-7.

8. Frimodt-Moller N, Ostri P, Pedersen K, Poulsen SR. Antibiotic prophylaxis in pulmonary surgery. Ann Surg 1982; 195:444-56.

9. Landis JR, Miller ME, Davis CS, Koch GG. Some general methods for the analysis of categorical data in longitudinal studies. Stat Med 1988;7:109-37.

10. Kirk RE. Experimental design. 2nd ed. Monterey, Calif: Brooks, 1982. 245-318.

11. BMDP statistical software manual. Los Angeles, Calif: University of California Press, 1990.

12. SAS Institute Inc. SAS user's guide statistics, version 5 edition. Cary, N.C.: SAS Institute Inc., 1990.

13. Truesdale R, D'alessandri R, Manuel V, Daicoff G, Kluge RM. Antimicrobial vs placebo prophylaxis in noncardiac thoracic surgery. JAMA 1979;241:12546.

14. Walker WS, Faichney A, Raychaudhury T. Wound prophylaxis in thoracic surgery: new approach. Thorax 1984; 39:121-4.

15. Tarkka M, Pokela R, Lepojarvi M, Nissinen J, Karkola P. Infection prophylaxis in pulmonary surgery: a randomized prospective study. Ann Thorac Surg 1987;44:508-13.

16. Peyrin JC, Brichon PY, Girardet P, et al. Prophylactic antibiotics in pulmonary surgery: a prospective randomized double blind study. CIPI, 40eme Congres de la SPILF, Nice, France, 1990.

17. Olak J, Jeyasingham K, Forrester-Wood C, et al. Randomized trial of one dose versus six dose cefazolin prophylaxis in elective general thoracic surgery. Ann Thorac Surg 1991;51:956-8. 